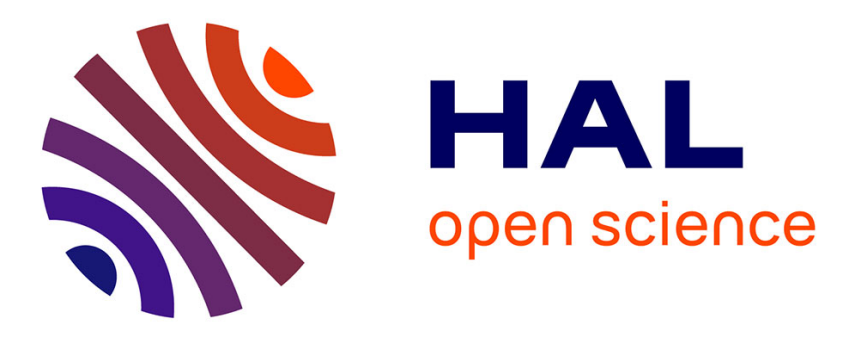

\title{
Prolongation of the lifetime of guided discharges triggered in atmospheric air by femtosecond laser filaments up to $130 \mu \mathrm{s}$
}

Léonid Arantchouk, Bruno Honnorat, Emmanuelle Thouin, Guillaume Point, A. Mysyrowicz, Aurélien Houard

\section{To cite this version:}

Léonid Arantchouk, Bruno Honnorat, Emmanuelle Thouin, Guillaume Point, A. Mysyrowicz, et al.. Prolongation of the lifetime of guided discharges triggered in atmospheric air by femtosecond laser filaments up to $130 \mu \mathrm{s}$. Applied Physics Letters, 2016, 108 (17), pp.173501. 10.1063/1.4947273 . hal-01314451v2

\section{HAL Id: hal-01314451 \\ https://hal.sorbonne-universite.fr/hal-01314451v2}

Submitted on 18 May 2016

HAL is a multi-disciplinary open access archive for the deposit and dissemination of scientific research documents, whether they are published or not. The documents may come from teaching and research institutions in France or abroad, or from public or private research centers.
L'archive ouverte pluridisciplinaire HAL, est destinée au dépôt et à la diffusion de documents scientifiques de niveau recherche, publiés ou non, émanant des établissements d'enseignement et de recherche français ou étrangers, des laboratoires publics ou privés. 


\title{
Prolongation of the lifetime of guided discharges triggered in atmospheric air by femtosecond laser filaments up to $130 \mu \mathrm{s}$
}

\author{
L. Arantchouk ${ }^{1,2, a)}$, B. Honnorat ${ }^{1}$, E. Thouin ${ }^{1}$, G. Point ${ }^{1}$, A. Mysyrowicz ${ }^{1}$ and A. \\ Houard $^{1}$ \\ ${ }^{1}$ LOA, ENSTA ParisTech, CNRS, Ecole polytechnique, Université Paris-Saclay, 828 bd des Maréchaux, 91762 \\ Palaiseau cedex, France \\ ${ }^{2}$ Laboratoire de Physique des Plasmas, CNRS, Ecole Polytechnique, UPMC, Université Paris-Sud, 91128 Palaiseau, \\ France

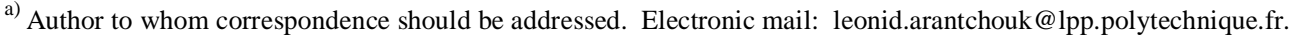

\begin{abstract}
The triggering and guiding of electric discharges produced in atmospheric air by a compact $100 \mathrm{kV}$ Marx generator is realized in laboratory using an intense femtosecond laser pulse undergoing filamentation. We describe here an approach allowing extending the lifetime of the discharges by injecting a current with an additional circuit. Laser guiding discharges with a length of $8.5 \mathrm{~cm}$ and duration of $130 \mu \mathrm{s}$ were obtained.
\end{abstract}

In the last decade femtosecond laser filaments has proved to be a powerful tool to trigger and guide electric discharges in atmospheric air ${ }^{1}$ with gap length of a few meters ${ }^{2-6}$. The weakly ionized plasma column and subsequent low density channel generated by laser filaments allow the precise triggering and guiding of electric discharges between two electrodes with a significant reduction of the breakdown voltage ${ }^{7-9}$. This effect is potentially useful for the development of laser lightning rod 4, 10-11, high-voltage, high-current switches ${ }^{12}$, or virtual plasma antennas ${ }^{13-14}$.

For applications such as plasma antennas, extension of the filament plasma lifetime is needed, since the plasma from the filament recombines in a few nanoseconds, seriously limiting the bandwidth of antennas to frequencies $\mathrm{v}>10^{9} \mathrm{~Hz}$. This can be done using additional femtosecond or nanosecond laser pulses ${ }^{15-17}$ but this technique is particularly complex and the resulting plasma is limited to a few $\mu$ s. Injection of electric current through guided discharges appears to be a more promising way. The duration of the guided discharge mostly depends on the high voltage (HV) source, with a typical duration on the order of $100 \mathrm{~ns}^{2-4,14}$. In several publications, a Marx generator was used as the HV source to produce meter scale guided discharges. In this case, the discharge duration is defined by the product of the Marx "stack" capacitance $\mathrm{C}_{\operatorname{marx}}$ and a discharge load $\mathrm{R}_{\text {load }}$. In Ref. 18, a compact Marx generator was used to create a $\sim 21 \mathrm{~cm}$ guided discharge of duration about $600 \mathrm{~ns}$ due to the mentioned Marx capacitance $\mathrm{C}_{\max } \sim 2 \mathrm{nF}$ and the discharge load resistance $\mathrm{R}_{\mathrm{d}} \sim 300 \Omega$. In this letter we describe a method, which allows prolonging this parameter up to $130 \mu \mathrm{s}$.

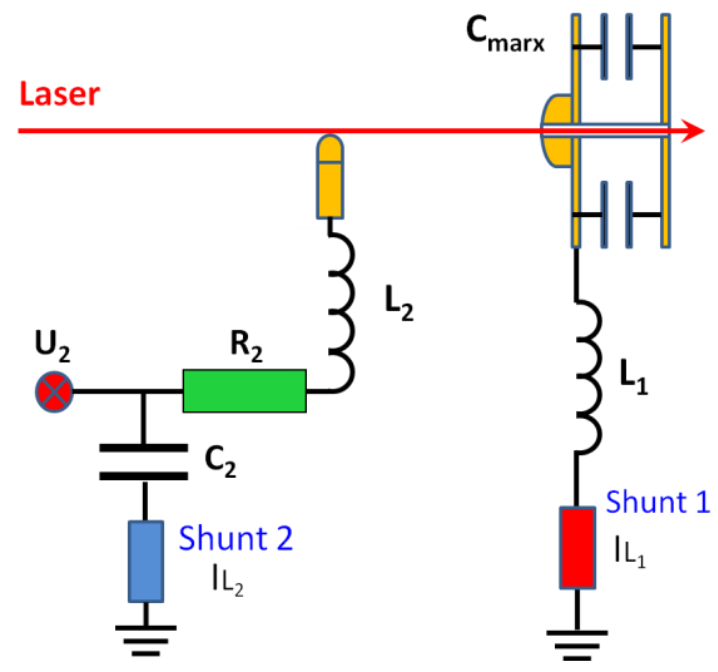

FIG. 1. Schematic view of the experimental set-up with a HV source (Marx generator) and an additional circuit $\mathrm{R}_{2} \mathrm{~L}_{2} \mathrm{C}_{2}$.

The experiment setup is presented in Fig. 1. The circuit is composed of two parts. The first part is a Marx generator described in 18. For this experiment the generator was composed of 5 stages charged up to $20 \mathrm{kV} \mathrm{DC}$, resulting in $100 \mathrm{kV}$ output pulse with a negative polarity. An inductance $\mathrm{L}_{1}$ was connected to the generator output electrode and served as a load up to the moment when the Marx pulse produces a breakdown in the inter-electrode gap. The Marx output electrode has a cylinder form with an axial hole allowing the laser beam to enter in the generator and to trigger it. The second electrode is a round finger with a $5 \mathrm{~mm}$ radius. As described in Ref. 18, a chirped pulse amplified laser system emitting at a wavelength of $800 \mathrm{~nm}$ is used to produce the filaments between the two electrodes and inside the Marx generator. The laser pulse with 
energy of $200 \mathrm{~mJ}$, pulse duration of $700 \mathrm{fs}$ and diameter of $30 \mathrm{~mm}$ FWHM is focused by a convex lens (focal $\mathrm{f}=5 \mathrm{~m}$ ), generating a bundle of plasma channels over $1.5 \mathrm{~m}$ before the geometrical focus of the lens (see characterization of the filament bundle in ref 19). The geometrical focus of the beam was positioned $30 \mathrm{~cm}$ after the Marx entrance electrode in order to trigger the Marx generator as well as the guided discharge.
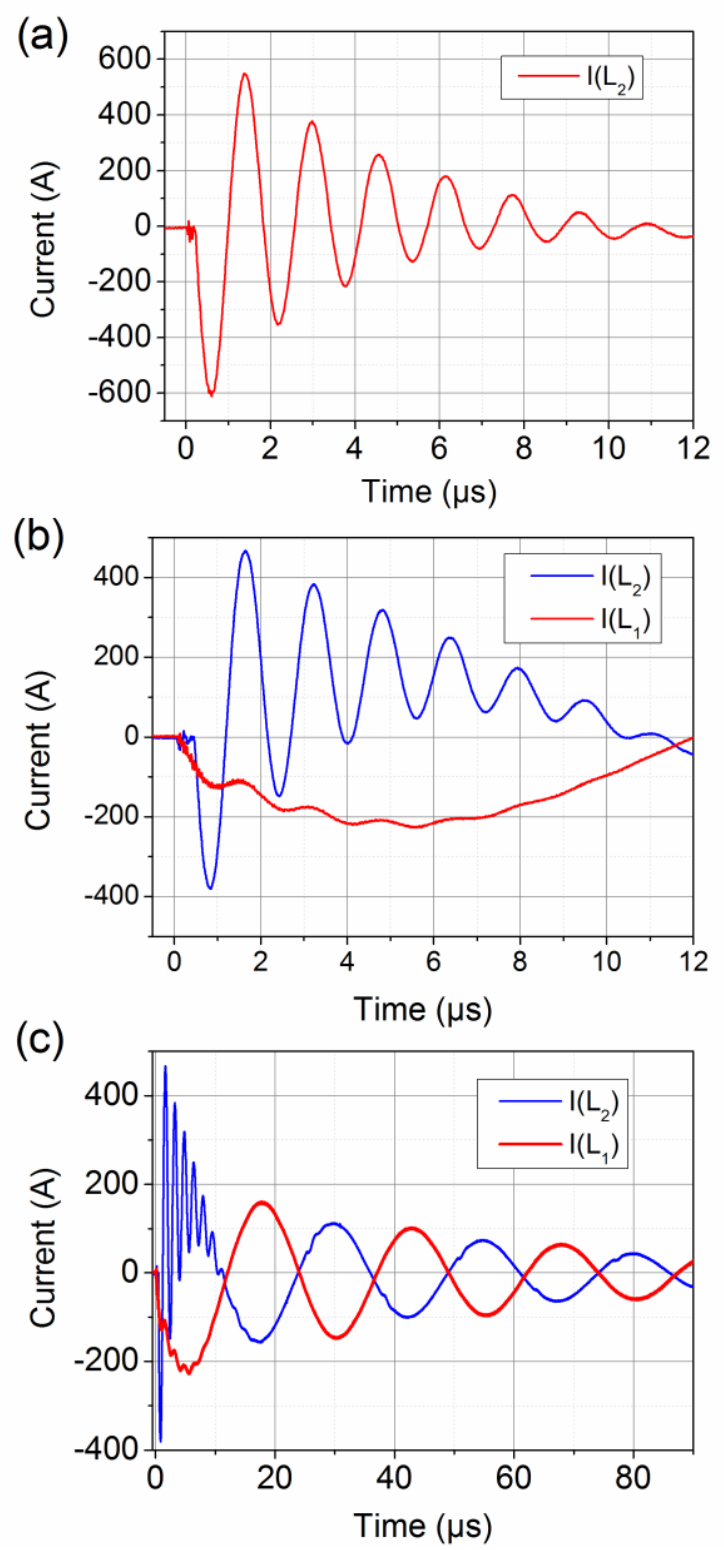

FIG. 2. Current signals $\mathrm{I}_{\mathrm{L} 1}$ and $\mathrm{I}_{\mathrm{L} 2}$ with $\mathrm{R}_{2}=10 \Omega$ : (a) without any polarization: $\mathrm{I}_{\max }(\mathrm{HF}) \approx-600 \mathrm{~A} ; \mathrm{I}_{\max }(\mathrm{BF}) \approx-45 \mathrm{~A}$; (b) $\mathrm{U}_{\mathrm{C} 2}=-20 \mathrm{kV}$ : two first $\mathrm{HF}$ peaks are $\mathrm{I}_{\max }(\mathrm{HF}) \approx-390 \mathrm{~A}$ and $\mathrm{I}_{\max }(\mathrm{HF}) \approx 470 \mathrm{~A}$. $\mathrm{I}_{\text {peak }}(\mathrm{BF}) \approx-220 \mathrm{~A}$.

The second part of the circuit consists of a capacitor $\mathrm{C}_{2}$, a resistor $\mathrm{R}_{2}$, and an inductance $\mathrm{L}_{2}$. To create a polarity regime, the capacitor is charge up to $\pm 20 \mathrm{kV}$ DC. The circuit is operating as follows. The laser passes first between the two electrodes and then enters into the Marx generator from its output side. This configuration gives the shortest delay between the HV Marx pulse and the gap breakdown ${ }^{18}$. The breakdown generates a plasma column between the electrodes, which makes possible discharging the capacitor $\mathrm{C}_{2}$ through $\mathrm{L}_{2}, \mathrm{R}_{2}$ and $\mathrm{L}_{1}$. There is almost no current from the capacitor $\mathrm{C}_{2}$ discharging through the Marx because of well matched parameters of the circuit. Thus a current is injected in the plasma channel prepared by the HV charged source with help of the low voltage charged circuit.

The operation of the circuit is monitored by means of two shunts. The first one measures the current $\mathrm{I}_{\mathrm{L} 1}$ flowing through the coil $\mathrm{L}_{1}$, while the second shunt measures the current $\mathrm{I}_{\mathrm{L} 2}$ flowing through the coil $\mathrm{L}_{2}$.

To demonstrate the proposed method a minimal duration of $130 \mu \mathrm{s}$ has been chosen for the discharge. Based on the previous study with the Marx generator ${ }^{18}$ we chose parameters of the circuit producing an "effective" electric field $\mathrm{U}_{\operatorname{mar} x} / \mathrm{L}>$ 
$10 \mathrm{kV} / \mathrm{cm}$ with a breakdown delay smaller than 300 - $400 \mathrm{~ns}$ (where $\mathrm{U}_{\operatorname{marx}}$ is the Marx output voltage and $L$ is the gap length). Therefore we started the experiments with a gap $\mathrm{L}=85 \mathrm{~mm}$ and an inductance $\mathrm{L}_{1}>400 \mu \mathrm{H}$, which provides no more than $5 \%$ drop of the output Marx voltage during the breakdown delay. To inject the Marx discharge into the $85 \mathrm{~mm}$ gap, we need $\mathrm{L}_{2} \ll<\mathrm{L}_{1}$, while the protection of the capacitor $\mathrm{C}_{2}$ from the Marx $100 \mathrm{kV}$ pulse brings the condition $\mathrm{C}_{2}>\mathrm{C}_{\operatorname{marx}}$. To fulfill these conditions the following circuit parameters were chosen: $\mathrm{L}_{2}=29 \mu \mathrm{H}, \mathrm{C}_{2}=37 \mathrm{nF}$, and $\mathrm{L}_{1}=404 \mu \mathrm{H}$.

Typical experimental signals of the currents $\mathrm{I}_{\mathrm{L} 1}$ and $\mathrm{I}_{\mathrm{L} 2}$ are shown in Fig. 2 in the case of oscillating regime with a small resistance $\mathrm{R}_{2}$. Two cases are presented here: a) without any polarization: only high frequency oscillations (HF) defined by the circuit $\mathrm{C}_{\operatorname{marx}}-\mathrm{L}_{2}-\mathrm{R}_{2}-\mathrm{C}_{2}$ are observed. Their period is $\mathrm{T}(\mathrm{HF}) \approx 2 \pi\left(\mathrm{C}_{\operatorname{marx}} \times \mathrm{L} 2\right)^{0.5}=1.6 \mu \mathrm{s}$, and the amplitude of the first current peak is about $600 \mathrm{~A}$. In this case effective discharge duration is about $10 \mu \mathrm{s}$. b) The capacitor $\mathrm{C}_{2}$ is charge negatively up to $\mathrm{U}_{\mathrm{C} 2}=-20 \mathrm{kV}$. In this case the low frequency (LF) oscillations with period $\mathrm{T}(\mathrm{LF}) \approx 2 \pi(\mathrm{C} 2 \times \mathrm{L} 1)^{0,5} \approx 25 \mu$ s produced by the circuit $\mathrm{C}_{2}-\mathrm{L}_{2}-\mathrm{L}_{1}$ become the most pronounced. When a negative polarization $\mathrm{U}_{2}$ is applied, the breakdown voltage reaches 80 $\mathrm{kV}$, while in the case of positive polarization it reaches $120 \mathrm{kV}$. As a consequence, the breakdown delay decreases from 210 $\pm 45 \mathrm{~ns}$ to $148 \pm 21 \mathrm{~ns}$ when the polarity is changed. The current amplitude also depends on the applied polarity $\mathrm{U}_{2}$. The regime of the negative polarization produces smaller $\mathrm{HF}$ amplitude $\left(\mathrm{I}_{\text {peak }}=-390 \mathrm{~A}\right.$ for $\mathrm{U}_{\mathrm{C2}}=-20 \mathrm{kV}$ against $\mathrm{I}_{\text {peak }}=-750 \mathrm{~A}$ for $\left.\mathrm{U}_{\mathrm{C} 2}=20 \mathrm{kV}\right)$ and higher $\mathrm{LF}$ amplitude $\left(\mathrm{I}_{\text {peak }}=-220\right.$ A for $\mathrm{U}_{\mathrm{C} 2}=-20 \mathrm{kV}$ against $\mathrm{I}_{\text {peak }}=135 \mathrm{~A}$ for $\left.\mathrm{U}_{\mathrm{C} 2}=20 \mathrm{kV}\right)$. Due to the $\mathrm{LF}$ current injection, the effective discharge duration becomes longer than $100 \mu$ s. Note in Fig. 2(c), that the LF currents $\mathrm{I}_{\mathrm{L} 1}$ and $\mathrm{I}_{\mathrm{L} 2}$ are opposite but with the same amplitudes, meaning that the LF current circulates inside the same circuit loop.

The resistance $R_{2}$ allows changing the damping factor of the circuit. To obtain an alternative regime we used $R_{2}=10 \Omega$, which is much smaller than the impedances of HF and LF circuits $\sim 110 \Omega$. A fitting of the current signals considering a damped sinusoidal function allows one to determine the total discharge resistance $R_{\text {disch }}$ and the circuit parameters. The total resistance varies in the range between $16 \Omega$ and $23 \Omega$ depending of experiment series. These values exceed the resistance $R_{2}$ $=10 \Omega$. Measurements with different gap lengths $L$ in the range $15-85 \mathrm{~mm}$ revealed that $R_{\text {disch }}$ does not depend of this gap length. It means that the measured guided discharge resistance is mostly due to some contact processes in the vicinity of the electrodes. It is also interesting to note that $R_{\text {disch }}$ remains remarkably constant during the discharge.

The guided discharge was imaged with help of a 16-bit intensified charge-coupled device camera (ICCD) operated with a gate opening time of $100 \mathrm{~ns}$. Examples of ICCD images for different delays in the range $\tau=15-130 \mu \mathrm{s}$ are presented in Fig. 3. A dilatation factor of $\mathrm{Y} / \mathrm{X} \approx 4$ has been used to present ICCD images for a better visibility of the plasma cross section. An integrated image of the discharge is also presented to show the electrode geometry (Fig. 3(d)). This serie of instantaneous images reveals that the guided discharge conserves the same linear shape during the whole life of the discharge, up to $130 \mu$ s. One should also note that the plasma is brighter close to the Marx electrode.

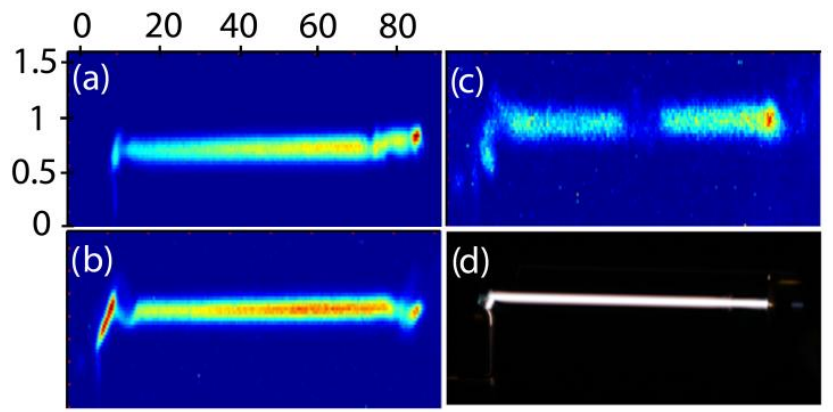

FIG. 3. ICCD images of the guided discharge taken at a delay $\tau=15 \mu \mathrm{s}$ (a), $60 \mu$ s (b) and $130 \mu \mathrm{s}$ (c) and time integrated image of the guided discharge (d). The spatial scale is indicated in $\mathrm{mm}$ and intensity color scale is normalized. The Marx generator is on the right side, and the laser beam comes from the left.

Fig. 4(a) shows a typical transverse luminosity profile integrated over $15 \mathrm{~mm}$. To analyze the temporal evolution of the plasma channel while minimizing artifacts due to discontinuities we integrated the luminosity profile with a threshold defined as the half maximum of the luminosity profile. Fig. 4(b) shows the temporal evolution of the integrated discharge luminosity measured at each maxima of discharge current. The points are well fitted by an exponential curve with a decay time constant of $24 \mu \mathrm{s}$ (red curve). It is worth noting that the current decay time is almost two times longer, with a value of $42 \mu \mathrm{s}$. It is an indication that the total light luminosity is proportional to the square of the current. On should note that with a higher temporal resolution the plasma luminosity should present an oscillating decay similar to the square of the current signal. 

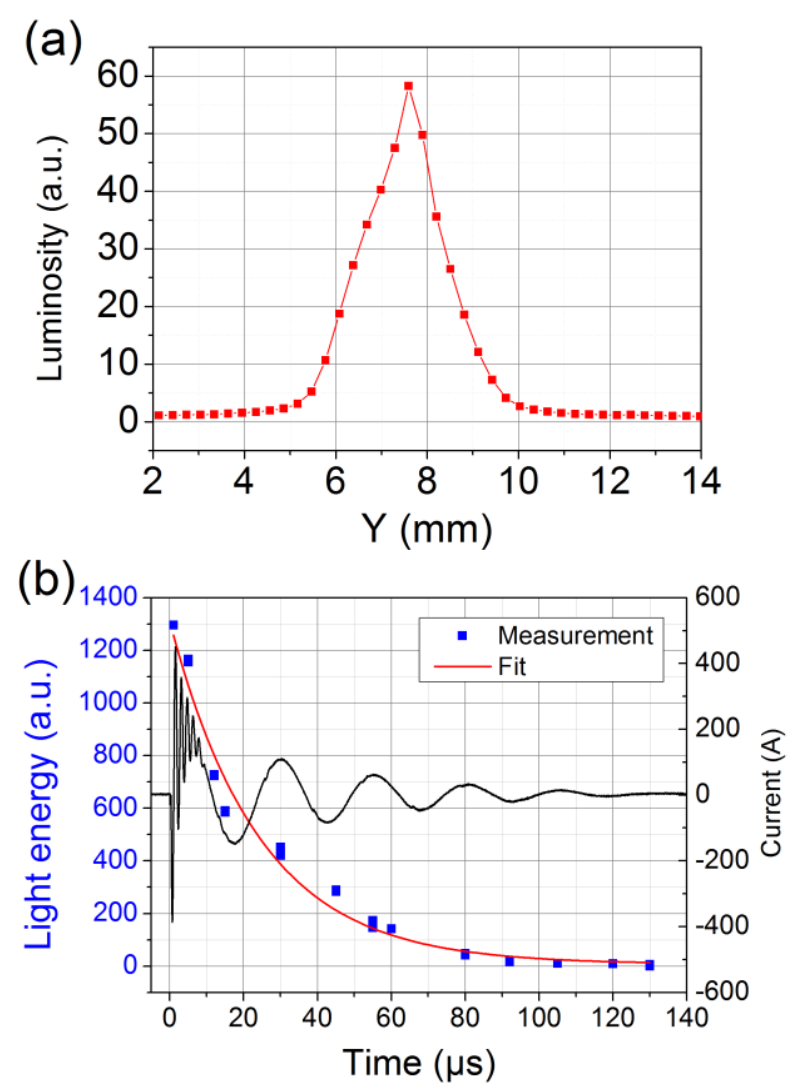

FIG. 4. a) Plasma transverse luminosity profile measured by the ICCD camera and averaged over a 15 mm length. (b) Temporal evolution of the integrated discharge luminosity (blue squares) and the current signal (black line) measured in the oscillating regime (R=10 $\Omega$ ). The results are well approximated by an exponential decay fit with a constant of $24 \mu \mathrm{s}$ (red line).

The treatment described above allows us to control numerically the geometrical form of the guided discharge. We observe ICCD images with different percentage of guidance (70-100\%). As illustrated in Fig. 5, in some cases the guided discharge presents discontinuities that we attribute to "jumps" of the initial current from one filament to the other. Similar discontinuities were observed in the guided discharges produced in our spark gap, Marx and Tesla experiments 9,12,14,18. The average FWHM measured on the homogeneous parts of the images changes very weakly during $130 \mu$ s with a value of $2.1 \pm$ $0.2 \mathrm{~mm}$.

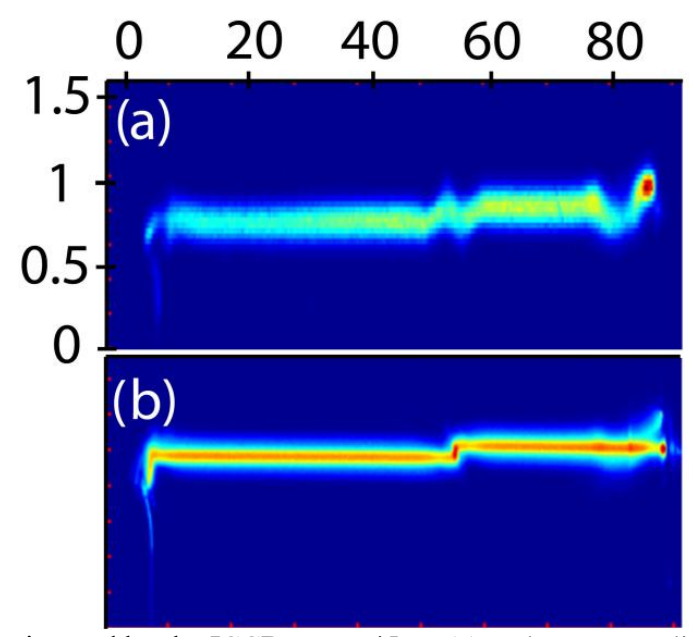

FIG. 5. Current "jump" event imaged by the ICCD at $\tau=45 \mu \mathrm{s}$ (a) and corresponding time integrated picture (b). 
The same measurements have been carried out in a damped current regime, when a ballast resistance $\mathrm{R}_{2}=100 \Omega$ close to the circuit impedance was used. In this case with a positive polarization (see Fig. 6), one observe two short current peaks ( 0. 5 and $1.5 \mu$ s) with amplitudes of -500 and $165 \mathrm{~A}$ followed by a relatively long tail with a maximum about $75 \mathrm{~A}$.

Fig. 6(b) and (c) present the ICCD images taken at times $\tau=1 \mu \mathrm{s}, 14 \mu \mathrm{s}$ and $20 \mu \mathrm{s}$ in the case of damped regime. The luminosity behavior is very different from the oscillating regime. It presents a rapid drop in the first $4 \mu$ s followed by a relatively slow evolution. It is interesting to note that the evolution of the plasma width in this regime is also significantly different. Its value decreases from $1.9-2.0 \mathrm{~mm}$ at the current beginning to $1.6 \mathrm{~mm}$ at its end $(\tau=20 \mu \mathrm{s})$ when the current becomes close to zero (Fig. 6(d)).
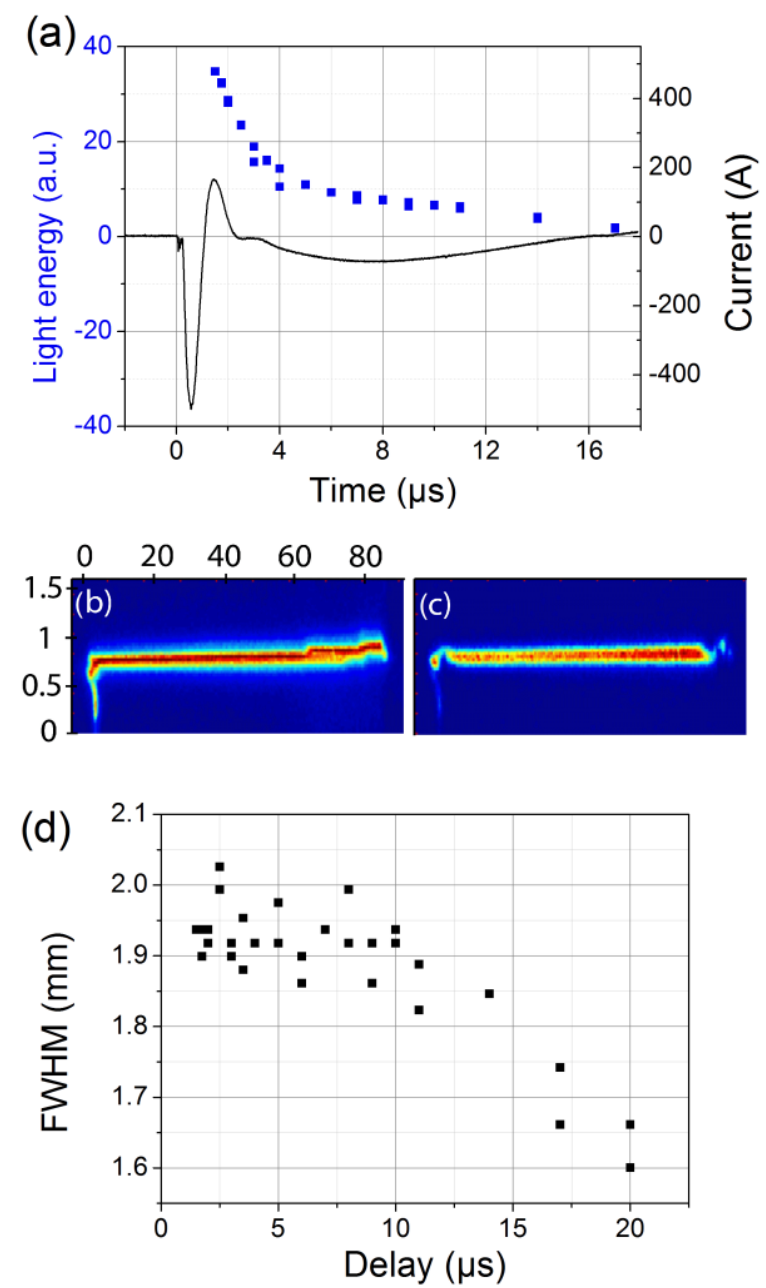

FIG. 6. (a) Temporal evolution of the light emission of the discharge (blue squares) and the current signal (black line) measured in the damped regime. (b) and (c) ICCD images taken at $\tau=14$ and $20 \mu \mathrm{s}$ in the case of damped oscillations. (d) Average full width at half maximum of ICCD image profiles as a function of time. Resistance $R_{2}=100 \Omega$.

In conclusion, we have increased the lifetime of a laser guided discharge up to $130 \mu$ s by injecting a secondary current with a $20 \mathrm{kV}$ charged additional circuit. The guided discharge was produced in atmospheric air by shorting an inter-electrode gap $85 \mathrm{~mm}$ with help of a compact $100 \mathrm{kV}$ Marx generator triggered by femtosecond laser source. We have measured a discharge resistance of $\sim 10-20 \Omega$, mostly due to contact processes in the vicinity of the electrodes. This result is promising for the development of plasma antenna, where electric circuit could be used in conjunction with intense ultra-short laser working at a $\mathrm{kHz}$ repetition rate ${ }^{20}$ to realize a quasi-permanent plasma column.

Finally, the guided discharge remains straight up to $130 \mu \mathrm{s}$. This surprising result might be due to the mechanism of suppression of turbulent decay exposed by Leonov et al. in Ref 21 or by the generation of the low density channel by the laser filament during the triggering of the discharge ${ }^{22,23}$. In a next step we will try to increase the guided discharge duration up to the millisecond range and investigate further the physical mechanism and the limitation of this long timescale guiding effect. 


\section{Acknowledgments}

This project has been supported by the French Direction Generale de l'Armement (Grant $N^{\circ}$ 2013.95.0901). The authors acknowledge technical support by Jérôme Carbonnel, Yves-Bernard André and Jean-Lou Charles and fruitful discussions with Michel Pellet, Sylvain Flajolet and Besma Larbi.

\section{References}

${ }^{1}$ A. Couairon and A. Mysyrowicz, Phys. Rep. 441, 47 (2007).

${ }^{2}$ H. Pepin D. Comtois, F. Vidal, C. Y. Chien, A. Desparois, T. W. Johnston, J. C. Kieffer, B. La Fontaine, F. Martin, F. A. M. Rizk, C. Potvin, P. Couture, H. P. Mercure, A. Bondiou-Clergerie, P. Lalande and I. Gallimberti, Phys. Plasmas 8, 2532 (2001).

${ }^{3}$ M. Rodriguez, R. Sauerbrey, H. Wille, L. Wöste, T. Fujii, Y.-B. André, A. Mysyrowicz, L. Klingbeil, K. Rethmeier, W. Kalkner, J. Kasparian, E. Salmon, J. Yu and J.-P. Wolf, Opt. Lett. 27, 772 (2002).

${ }^{4}$ B. Forestier, A. Houard, I. Revel, M. Durand, Y. B. André, B. Prade, A. Jarnac, J. Carbonnel, M. Le Nevé, J. C. de Miscault, B. Esmiller, D. Chapuis, and A. Mysyrowicz, AIP Advances 2, 012151 (2012).

${ }^{5}$ M. Henriksson, J.-F. Daigle, F. Théberge, M. Châteauneuf, and J. Dubois, Opt. Express 20, 12721 (2012).

${ }^{6}$ J.-F. Daigle, F. Théberge, P. Lassonde, J.-C. Kieffer, T. Fujii, J. Fortin, M. Châteauneuf, and J. Dubois, Appl. Phys. Lett. 103, 184101 (2013).

${ }^{7}$ F. Vidal, D. Comtois, C. Ching-Yuan, A. Desparois, B. La Fontaine, T.W. Johnston, J. Kieffer, H. P. Mercure, H. Pepin, F.A. Rizk, IEEE Trans. on Plasma Science 28418 (2000).

${ }^{8}$ S. Tzortzakis, B. Prade, M. Franco, A. Mysyrowicz, S. Hüller, and P. Mora, Phys. Rev. E 64, 57401 (2001).

${ }^{9}$ G. Point, Y. Brelet, L. Arantchouk, J. Carbonnel, B. Prade, A. Mysyrowicz, and A. Houard, Rev. Sci. Instr. 85, 123101 (2014).

${ }^{10}$ J. Kasparian, R. Ackermann, Y.-B. André, G. Méchain, G. Méjean, B. Prade, P. Rohwetter, E. Salmon, K. Stelmaszczyk, J. Yu, A. Mysyrowicz, R. Sauerbrey, L. Wöste, and J.-P. Wolf, Opt. Express 16, 5757 (2008).

${ }^{11}$ T. Fujii, M. Miki, N. Goto, A. Zhidkov, T. Fukuchi, Y. Oishi and K. Nemoto, Phys. Plasma 15, 013107 (2008).

${ }^{12}$ L. Arantchouk, A. Houard, Y. Brelet, J. Carbonnel, J. Larour, Y-B André and A. Mysyrowicz, Appl. Phys. Lett. 102, 163502 (2013).

${ }^{13}$ T. J. Dwyer, J. R. Greig, D. P. Murphy, J. M. Perin, R. E. Pechacek, and M. Raleigh, IEEE Trans. Antennas Propag. AP-32, 141 (1984).

${ }^{14}$ Y. Brelet, A. Houard, L. Arantchouk, B. Forestier, Y. Liu, B. Prade, J. Carbonnel, Y.-B. André and A. Mysyrowicz, App. Phys. Lett. 100, 181112 (2012).

${ }^{15}$ Z. Q. Hao, J. Zhang, Y.T. Li, X. Lu, X. H. Yuan, Z. Y. Zheng, Z. H. Wang, W. J. Ling and Z. Y. Wei Appl. Phys. B 80, 627-630 (2005).

${ }^{16}$ B. Zhou, S. Akturk, B. Prade, Y.-B. André, A. Houard, Y. Liu, M. Franco, C. D'Amico, E. Salmon, Z.-Q. Hao, N. Lascoux and A. Mysyrowicz, Opt. Express 17, 11450 (2009).

${ }^{17}$ P. Polynkin and J.V. Moloney, Appl. Phys. Lett. 99, 151103 (2011).

${ }^{18}$ L. Arantchouk, G. Point, Y. Brelet, J. Larour, J. Carbonnel, Y.-B. André, A. Mysyrowicz and A. Houard, Appl. Phys. Lett. 104, 103506 (2014).

${ }^{19}$ G. Point, Y. Brelet, A. Houard, V. Jukna, C. Milián, J. Carbonnel, Y. Liu, A. Couairon, and A. Mysyrowicz, Phys. Rev. Lett. 112, 223902 (2014).

${ }^{20}$ A. Houard, V. Jukna, G. Point, Y-B. André, S. Klingebiel, M. Schultze, K. Michel, T. Metzger, and A. Mysyrowicz, Opt. Express 24, 7437 (2016).

${ }^{21}$ S. V. Leonov, Y. I. Isaenkov and M. N. Shneider, Phys. Plasma 14, 123504 (2007).

${ }^{22}$ G. Point, C. Milián, A. Couairon, A. Mysyrowicz, and A. Houard, J. Phys. B, 48, 094009 (2015).

${ }^{23}$ G. Point, E. Thouin, A. Mysyrowicz, and A. Houard, Opt. Express 24, 6271 (2016). 